\section{Avaliação da qualidade da água e percepção higiênico-sanitária na área rural de Lavras, Minas Gerais, Brasil, 1999-2000}

\author{
Water quality evaluation in rural areas \\ of Lavras, Minas Gerais, Brazil, 1999-2000
}

\author{
1 Departamento de Medicina \\ Veterinária, Universidade \\ Federal de Lavras, \\ Lavras, Brasil. \\ 2 Escola de Veterinária, \\ Universidade Federal \\ de Minas Gerais, \\ Belo Horizonte, Brasil. \\ Correspondência \\ C. M. B. M. Rocha \\ Setor de Medicina Veterinária \\ Preventiva, Departamento \\ de Medicina Veterinária, \\ Universidade Federal de \\ Lavras. C. P. 3037, Lavras, $M G$ \\ 37200-000, Brasil. \\ rochac@ufla.br
}

\section{Abstract}

In addition to personal interviews, laboratory analyses were performed using 80 water samples from 45 rural areas that are crossed by the Água Limpa and Santa Cruz streams close to the city of Lavras, southern Minas Gerais State. The results allowed comparing the quality of water used for agriculture and the identification of determinant factors. The Água Limpa stream mostly crosses an area used primarily for housing and characterized by low schooling. Many houses are supplied by shallow water wells and have ordinary cesspits for human waste disposal. All springs are polluted. The Santa Cruz stream displays a different scenario. The land is used mostly for agricultural purposes. Most owners live in town, with widely varied levels of school, from none to university. The houses are supplied by surface water. Most of the springs are polluted. The perception by both home and land owners concerning quality of the drinking water is determined solely by the water's physical and organoleptic characteristics. Sanitary parameters are not taken into account. Moreover, there is no relationship between fecal contamination and the type of spring. Land use and anthropic activity are far more important than the type of spring for water quality.

Rural Sanitation; Water Quality; Domestic Water Consumption
Christiane Maria Barcellos

Magalhães da Rocha 1

Luciano dos Santos Rodrigues 2

Claudionor C. Costa 1

Paulo Roberto de Oliveira 2

Israel José da Silva ${ }^{2}$

Éder Ferreira Moraes de Jesus ${ }^{1}$

Renata G. Rolim 1

\section{Introdução}

A água é um elemento essencial à vida, porém pode trazer riscos à saúde em face de sua má qualidade, servindo de veículo para vários agentes biológicos e químicos 1,2,3,4,5; por isso, o homem deve estar atento aos fatores que podem interferir negativamente na qualidade da água que consome e no seu destino final.

O melhoramento nos serviços públicos de abastecimento de água reflete numa melhoria na saúde da população. Em São Paulo, por exemplo, em fins do século passado, iniciou-se o tratamento da água, e, logo em seguida, o índice de mortalidade por febre tifóide caiu de 120 para pouco mais de 20 por 100 mil habitantes. Em 1926, o índice foi reduzido a quase zero, graças à cloração das águas de abastecimento 6 .

Segundo o Ministério da Saúde 7, os grandes desafios da saúde ainda são, principalmente, as hepatites, a malária, a febre amarela, a cólera, a esquistossomose, o dengue, as leishmanioses, a hantavirose. Por essa lista, percebe-se a importância que ainda há nas doenças de veiculação hídrica ou que tenham como elo importante da cadeia o ambiente. Não há como combater essas enfermidades deixando de lado as populações rurais, nas quais a adequada captação e uso da água são sabidamente mais negligenciados do que nos grandes centros urbanos. 
Há grande importância em buscar o conhecimento da realidade rural, caracterizada por populações com menor acesso às medidas de saneamento 8 e pela presença de atividades agropecuárias altamente impactantes, podendo interferir na qualidade da água dos mananciais, muitos desses utilizados no abastecimento de água nas cidades, como os ribeirões Santa Cruz e Água Limpa, que são utilizados pela COPASA (Companhia Estadual de Saneamento de Minas Gerais) para abastecer o Município de Lavras. O diagnóstico da utilização da água e do conhecimento das pessoas nessas áreas sinaliza para os riscos à saúde dessas populações e da contaminação e poluição dos mananciais que nascem ou passam nessas regiões.

Com este estudo, objetivou-se estudar e comparar a qualidade da água dos mananciais, utilizada para consumo doméstico, dessedentação de animais e irrigação de culturas das propriedades situadas na zona rural das sub-bacias dos ribeirões Água Limpa e Santa Cruz, e buscar a percepção que os proprietários têm a respeito da água que utilizam e os fatores de risco envolvidos na contaminação e/ou poluição.

\section{Metodologia}

\section{Caracterização do universo de estudo}

As áreas de estudo estão inseridas no Município de Lavras, entre os meridianos 44057' W e $45^{\circ} 02^{\prime}$ W de longitude Oeste e entre os paralelos 21015' S e 21020' S, representando bacias contíguas e totalizando uma superfície conjunta de $42 \mathrm{Km}^{2}$, dos quais, $20,2 \mathrm{Km}^{2}$ correspondem ao ribeirão Água Limpa, e $21,8 \mathrm{Km}^{2}$, ao ribeirão Santa Cruz 9 .

O Município de Lavras está situado na região sul do Estado de Minas Gerais, Brasil, macrorregião III e microrregião do Alto Rio Grande, mesorregião sudoeste mineiro 10 .

O clima nessa região é caracterizado como temperado chuvoso com invernos secos e verões chuvosos. A temperatura média varia entre $18^{\circ}$ e $22^{\circ} \mathrm{C}$, e a precipitação total anual é de 1.300 a $1.400 \mathrm{~mm} 11$.

A região da sub-bacia Água Limpa caracteriza-se por alta ocupação da terra e se assemelha, em alguns pontos, a bairros de periferias de cidades, com residências quase contíguas, tendo, porém, alguns sítios e até mesmo pequenas fazendas e também olarias. Na sub-bacia Santa Cruz, as propriedades são fazendas com criação principalmente de bovinos leiteiros e/ou horta e mão-de-obra assalariada ou mista.

\section{Coleta e processamento de dados}

\section{- Amostragem}

A amostragem foi determinada tendo por base uma listagem de propriedades nas sub-bacias dos ribeirões Água Limpa e Santa Cruz, elaborada pela Hidrosistemas, para o projeto SIPAM (Sistema Integrado de Proteção aos Mananciais), por iniciativa da COPASA. Esses mananciais superficiais são utilizados para o abastecimento urbano após tratamento convencional.

Acrescentaram-se a essa lista dados obtidos por meio de consulta a lideranças de cada comunidade, que informavam os limites geográficos e a estimativa do número de propriedades da comunidade.

Os mananciais encontrados e utilizados para a comparação nesta pesquisa foram: (1) mananciais superficiais, que são aqueles que escoam na superfície terrestre, compreendendo córregos, ribeirões, rios, lagos e reservatórios artificiais; (2) mananciais subterrâneos, que se encontram totalmente abaixo da superfície terrestre, compreendendo os lençóis freáticos e profundos, sendo sua captação feita pelos poços rasos e profundos e (3) mananciais sub-superficiais, que são as partes dos mananciais subterrâneos (lençol freático) que afloram na superfície terrestre, tornando-se superficiais, denominados de nascentes.

O número de amostras correspondeu a $50 \%$ de cada tipo de manancial demonstrado na listagem elaborada para este projeto, sendo esses: subterrâneo, sub-superficial e águas superficiais. Porém, esse número não poderia ser inferior a dez. Manteve-se também a proporcionalidade dos tipos de mananciais por comunidade.

Nas propriedades, foram coletadas amostras de água de cada fonte utilizada para fins de consumo doméstico e/ou para os animais e/ou culturas, correspondendo a 50 e 30 fontes de água nas sub-bacias dos ribeirões Água Limpa e Santa Cruz, respectivamente.

\section{- Entrevistas}

Foram elaborados formulários para entrevistas semi-sistematizadas destinadas aos proprietários, com a finalidade de obter informações quanto à escolaridade do entrevistado, ao tipo de propriedade (casa ou fazenda) e ao número de residentes; mananciais e formas de captação utilizadas e consumo aproximado de água; tipos de filtros e outros métodos de tratamento utilizados; aspectos gerais sobre o destino do esgoto e lixo da família; qualidade de saúde e 
sua percepção sobre os fatores que poderiam contaminar e poluir os mananciais de água, sua importância e formas de evitar a contaminação.

Foram registradas, ainda, observações e impressões pessoais do entrevistador em relação a formas de captação e armazenamento da água, destino do esgoto e do lixo, aspectos gerais das atividades agropecuárias e quaisquer fontes de contaminação que merecessem maior atenção.

Os formulários foram aplicados em trinta propriedades, equivalentes a $60 \%$ do total de propriedades da bacia do ribeirão Água Limpa, entre os meses de janeiro e dezembro de 1999, e em 15 propriedades (100\%) de janeiro a julho de 2000, na sub-bacia do ribeirão Santa Cruz.

Três entrevistas da região do Água Limpa foram retiradas das análises por conterem discrepâncias ou inconsistências, porém, os dados de análise da água dessas localidades foram mantidos.

\section{- Coleta de água}

Concomitante à aplicação dos formulários de entrevistas, foram coletadas amostras de água para análise física, química e bacteriológica, num total de oitenta pontos representativos das duas sub-bacias, sendo cinqüenta pontos na sub-bacia do ribeirão Água Limpa e trinta pontos na sub-bacia do ribeirão Santa Cruz (Tabela 1).

As análises de $\mathrm{pH}$, temperatura e oxigênio dissolvido foram realizadas no local, e, em seguida, preenchida a ficha de análise de campo.

O número de amostras não é coincidente com o número de formulários aplicados, já que, na maioria das propriedades abordadas, existem mais de uma fonte de água utilizada.

\section{- Processamento dos exames laboratoriais de água}

As análises de água foram realizadas no Laboratório de Análises de Água do Departamento de Engenharia (LAADEG) da Universidade Federal de Lavras, de acordo com o Standard Methods for the Examination of Water and Wastewater 12 .

Os principais parâmetros analisados são descritos a seguir, de acordo com von Sperling ${ }^{13}$ :

a) Cor: responsável pela coloração da água, pode ser verdadeira, quando causada por substâncias orgânicas e inorgânicas, e aparente, quando causada por suspensões. Pode ser tóxica além de ser esteticamente indesejável.

b) Turbidez: representa o grau de interferência com a presença da luz através da água. É devida à presença de sólidos suspensos, de origem orgânica e inorgânica. Esteticamente indesejável.

c) Ferro e manganês: conferem sabor, odor, coloração e turbidez à água, além de depositarem-se nas tubulações, causando corrosão e incrustações.

d) Cloretos: é advindo da dissolução de sais, podendo, em altas concentrações, imprimir um sabor salgado à água, podendo também indicar a presença de águas residuárias.

e) Dureza: concentração de cátions multimetálicos em solução, principalmente cálcio e magnésio, causando sabor desagradável, podendo ter efeito laxativo, além de causar incrustações em tubulações de água quente e reduzir a formação de espuma, aumentando o gasto de sabão. Em alguns estudos realizados em áreas com maior dureza, verificou-se uma menor incidência de doenças cardíacas.

f) Oxigênio dissolvido: é de essencial importância para os organismos aeróbios; a presença de matéria orgânica no corpo d'água faz com que sua concentração diminua, pois esse é utilizado pelas bactérias na estabilização da matéria orgânica.

g) Demanda bioquímica de oxigênio: é uma forma indireta de avaliar-se a quantidade de carbono orgânico presente em um corpo d'água, sendo um importante parâmetro para avaliar-se o grau de poluição com matéria orgânica do corpo d'água.

i) Coliformes fecais: principal indicador da presença de contaminação fecal no corpo d'água.

\section{- Análise dos dados}

A metodologia para a análise das entrevistas, desde a construção dos formulários, assim como os processos de entrevista e a posterior análise dos dados e descrição dos resultados foram feitos conforme Rocha 14 , de acordo com Triviños 15, Gil 16 e Minayo 17.

Tabela 1

Número de amostras de água analisadas segundo o tipo de manancial e sub-bacia. Lavras, Minas Gerais, Brasil, 1999-2000.

\begin{tabular}{lcc}
\hline & Água Limpa & Santa Cruz \\
\hline Subterrâneo (poços rasos) & 26 & 3 \\
Sub-superficial (nascentes) & 9 & 9 \\
Superficial & 15 & 18 \\
Total & 50 & 30 \\
\hline
\end{tabular}


Para a análise das informações colhidas por entrevista, construiu-se um banco de dados, os quais foram analisados pelos programas Epi Info 6.04 (Centers for Disease Control and Prevention, Atlanta, Estados Unidos) e SPSS 11.0 (SPSS Inc., Chicago, Estados Unidos). Procedeu-se então à análise estatística descritiva de cada variável por meio da indicação de como variavam os indivíduos no grupo para cada variável e ressaltando o que é típico na amostra estudada para extrair os perfis.

Na montagem do banco de dados, foram feitas as seguintes etapas: a determinação de que cada uma das perguntas corresponderia a uma variável, codificação das variáveis, categorização das respostas abertas, codificação dos dados, formação do banco de dados. Realizaram-se análise estatística descritiva de cada variável e análises bivariadas por meio de correlação de Pearson para as variáveis quantitativas e qui-quadrado para qualitativas e comparação de médias por sub-bacias e por mananciais. Para comparação das médias de turbidez, coliformes fecais e demanda bioquímica de oxigênio entre os três tipos de mananciais: superficial, sub-superficial e subterrâneo, foi utilizada a ANOVA, com teste de homogeneidade das variâncias de Duncan. Já entre sub-bacias, a comparação de médias foi feita pela análise de Kruskal Wallis, já que os parâmetros não eram simétricos, e alguns não apresentam homogeneidade na variância.

Para as variáveis dependentes turbidez e coliformes fecais, foram feitas análises de regressão linear, levando-se em consideração os mananciais e sub-bacias como independentes. E ainda regressão logística para coliformes fecais com as variáveis qualitativas de percepção significativas nas análises univariadas.

\section{Resultados e discussão}

\section{Perfil das propriedades e proprietários da sub-bacia Santa Cruz}

Os proprietários da região estudada caracterizam-se por grande discrepância nos níveis de escolaridade (Figura 1). A maioria dos proprietários não reside na propriedade.

Em $60 \%$ das propriedades, o consumo de água é maior que 500 litros/dia, ao passo que, nos outros $40 \%$ das propriedades, o consumo é inferior ou inexistente em determinadas épocas do ano. Em $67 \%$ das propriedades, utilizamse o filtro à vela de porcelana e recipiente de barro (96\%). Sessenta por cento não souberam informar a forma de limpeza das velas, e o res- tante emprega métodos tradicionais, com substâncias abrasivas como sal, açúcar e bucha. As freqüências de limpeza das velas variam entre 15 a 30 dias, porém, $64 \%$ não opinaram. Poucos entrevistados fazem algum tratamento que vise a eliminar microrganismos da água, e desses, um (7\%) informou ferver, e três (20\%) utilizam cloro. Sessenta e sete por cento nunca realizaram análise de água e citam apenas características físicas (cor, odor, sabor e material em suspensão) como importantes para avaliar a qualidade. Os 33\% restantes demonstraram preocupação com contaminação ou desinfecção.

Todos os proprietários possuem banheiro, e a maioria utiliza a fossa absorvente como destino dos efluentes do banheiro. O destino do lixo gerado na propriedade é principalmente a incineração (68\%). Em apenas $20 \%$, havia recolhimento público do lixo. Outras formas de eliminação dos resíduos sólidos são adotadas individualmente. Houve relatos de destinação final do lixo nos arredores ou em áreas de erosão (no desbarrancado). O destino da água servida é principalmente a céu aberto (Figura 2).

Em relação às atividades agropecuárias, predominou-se, como atividade pecuária, a bovinocultura (93,3\%); 33\% das propriedades possuíam, como atividade complementar, a suinocultura e/ou avicultura; $87 \%$ das propriedades possuíam algum tipo de cultura, sendo: horticultura (33\%), cultura do milho $(27 \%)$ e café (20\%). A mão-de-obra mais utilizada é a assalariada $(73 \%)$ ou conjunta (13\%) (assalariada mais familiar), sendo cinco (5) o número máximo de empregados encontrados na propriedade.

Em $60 \%$ das propriedades, a água para os animais provém da mesma fonte que a de consumo doméstico. O gado possui bebedouro em 87\% das propriedades, e os proprietários afirmam que a água utilizada é de boa qualidade. A limpeza das instalações dos animais é feita principalmente por meios físicos (80\%), como o uso de enxada, vassoura e água com pressão, por serem instalações simples com pisos que não permitem ser lavados ou desinfetados. Geralmente, o esterco recolhido é colocado em culturas ou vendido (73\%). Cuidados preventivos básicos com o rebanho são citados por $93 \%$ dos proprietários, como as vacinas contra febre aftosa, raiva e manqueira. Oitenta por cento afirmam não ter ocorrências de doenças.

Sessenta e seis por cento dos proprietários relatam não usar a irrigação, e o método mais utilizado por aqueles que a utilizam é a aspersão (54\%). Noventa e quatro por cento utilizam adubo químico; e $64 \%$ não utilizam defensivos agrícolas; $56 \%$ dos proprietários afirmaram que têm ocorrido doenças nas culturas. 
O principal destino das embalagens usadas na criação/cultura é a incineração (60\%), apenas dois (13\%) têm recolhimento público, e os três restantes enterram ou jogam nos arredores ou reutilizam. Sessenta por cento dos entrevistados afirmam ter assistência técnica, sendo essa esporádica na maioria das vezes $(77,8 \%)$.

Foram levantadas trinta fontes de água utilizadas no consumo doméstico e agropecuário, sendo quatro subterrâneas (poços rasos), oito sub-superficiais (nascentes) e 14 superficiais (ribeirão, córrego, represa, rego). A captação das nascentes é feita em regos escavados (50\%), tornando suas águas superficiais.

Nas análises de água realizadas, constatouse que $93 \%$ das amostras apresentaram número de coliformes fecais acima do padrão de potabilidade, de acordo com a Portaria $n .36$ 18, com valores também superiores aos estabelecidos para os corpos d'água da classe 2, de acordo com a Resolução CONAMA n. 35719. Também ficaram fora do padrão: oxigênio dissolvido (87\%); turbidez (70\%); ferro total $(60 \%)$; cor $(57 \%) ; \mathrm{pH}(47 \%)$ e sólidos totais (3\%). Na ANOVA, não foi encontrada associação entre o tipo de manancial e demanda bioquímica de oxigênio ou coliformes fecais, como era esperado. Apenas a turbidez foi diferente entre os mananciais $(p=0,004)$. Na análise por regressão linear para águas superficiais em relação aos poços rasos e nascentes em conjunto, foi encontrada uma $\mathrm{OR}=3,0$, com o intervalo de confiança variando de 1,3 a 4,7 ( $\mathrm{p}=0,001)$. O modelo não foi ajustado por outros parâmetros, pois aqueles testados não demonstraram melhoria em seu poder explicativo.

\section{Perfil das propriedades e proprietários da sub-bacia Água Limpa}

As propriedades da região estudada dividemse em duas comunidades: Serrinha, que tem como atividade predominante as olarias (52\%), e Ponte Alta, onde se situam também pequenos sítios.

O perfil mostra que $100 \%$ dos proprietários residem no local, e $59 \%$ possuem o primeiro grau completo (Figura 1). A maior parte das propriedades consomem até 500 litros diários de água (68\%) e possuem banheiro (89\%). Em $67 \%$, há apenas um banheiro por propriedade, sendo o destino mais utilizado de dejetos a fossa do tipo absorvente (85\%). O principal destino do lixo é a incineração (67\%), e $7 \%$ têm recolhimento público. Porém, 26\% citaram jogar em qualquer lugar. Trinta por cento das embalagens são lançadas a céu aberto, a incineração é a segunda forma de destinação (26\%), 7\% en-
Figura 1

Grau de escolaridade dos proprietários entrevistados nas regiões das sub-bacias dos ribeirões Água Limpa e Santa Cruz.

Lavras, Minas Gerais, Brasil, 1999-2000.

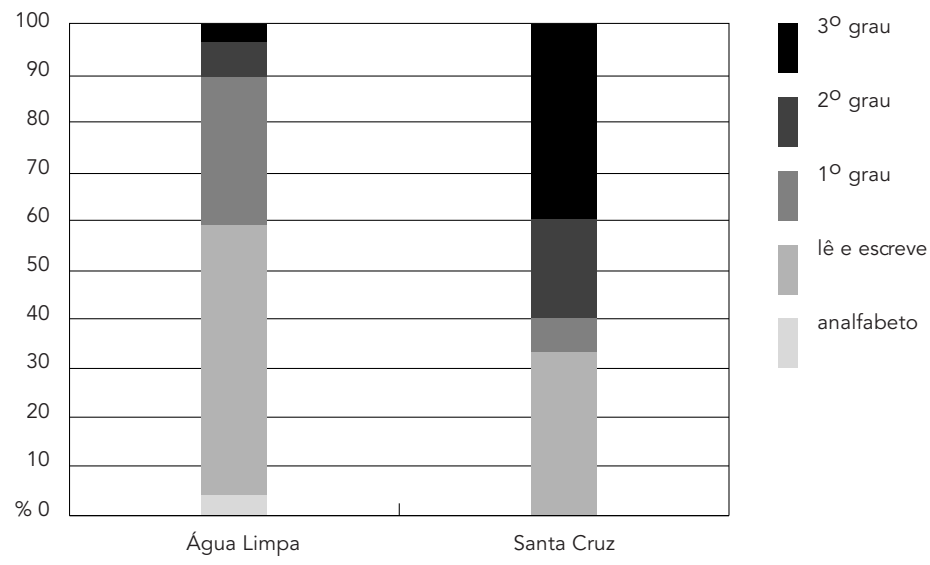

Figura 2

Destino da água servida nas propriedades nas regiões das sub-bacias dos ribeirões Água Limpa e Santa Cruz. Lavras, Minas Gerais, Brasil, 1999-2000.

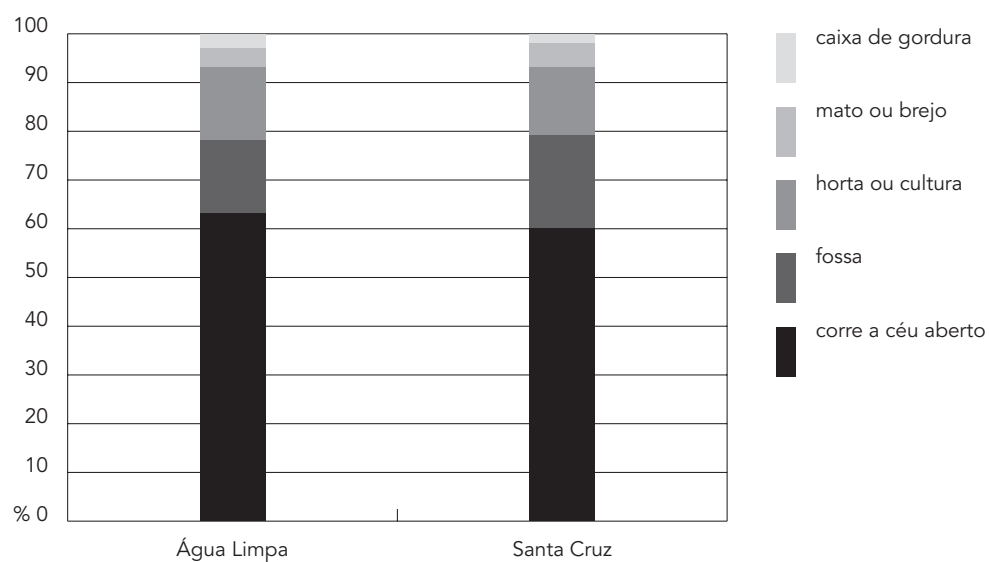

terram, e $4 \%$ citam reutilizá-las. O destino das águas residuárias domésticas pode ser visto na Figura 2.

Entre as propriedades, $78 \%$ possuem algum tipo de atividade pecuária, $48 \%$ têm bovinocultura de leite, e o mesmo número possui produção de suínos e aves. Em $67 \%$, há alguma atividade agrícola, sendo a mais freqüente a horti- 
cultura (56\%). Sete (26\%) utilizam irrigação, principalmente por rega. A mão-de-obra utilizada é familiar (96\%). A maioria (83\%) informa tomar os cuidados sanitários com os animais; porém, grande parte cita utilizar apenas vacinas, e $81 \%$ não têm assistência técnica. O esterco dos animais é freqüentemente utilizado como adubo, sendo armazenado em esterqueiras ou vendido. A limpeza das instalações não é feita $(30 \%)$ ou é feita apenas por métodos físi$\cos (33 \%)$, principalmente por serem instalações bem rústicas, com chão de terra batida.

Dos entrevistados, $56 \%$ afirmam não fazerem qualquer tratamento na água de bebida; porém, apenas 7\% não utilizam a filtração, sendo $82 \%$ pelo filtro de barro e vela. Desses, $91 \%$ limpam as velas com substâncias abrasivas, como sal, açúcar ou bucha. Porém, outros tratamentos são raros, pois $74 \%$ não fazem desinfecção, e apenas três utilizam o cloro para fazêla. Há confusão quanto ao que entendem por tratamento, que pode ser notada quando 15 dos entrevistados que afirmaram não fazer qualquer tratamento na água, 13 utilizavam filtro de vela, dois desinfetavam com cal, e um, com cloro. Dos que responderam tratar a água, todos utilizavam filtro, e apenas dois desinfetavam com cloro, e dois ferviam a água de beber. E dos três que responderam não saber, todos utilizavam filtro, e dois desinfetavam com cal.

Grande parte dos entrevistados (93\%) nunca fez qualquer análise laboratorial da água. Quando questionados sobre as características de importância na água doméstica, 67\% citam apenas aspectos físicos (transparência, sabor e odor), $26 \%$ citam que deve ser filtrada, fervida ou tratada, e apenas um $(3,7 \%)$ levantou a importância de o local de captação estar livre de fezes. Interessante foi que $52 \%$ consideram que as características da água para animais devem ser semelhantes à do consumo humano.

Sobre a qualidade da água da propriedade, $15 \%$ citavam que a água consumida apresentava alguma cor, $4 \%$ citaram que havia odor, e $78 \%$ que percebem sujeira na água. Porém, a ocorrência de doenças só foi citada em $11 \%$ das propriedades, e nos animais em nenhuma delas.

Foram levantadas 50 fontes de água, sendo 26 subterrâneas ( 25 poços rasos, 1 poço artesiano), 9 águas sub-superficiais (nascentes) e 15 superficiais (ribeirão, córrego, represa, açude). A captação das águas subterrâneas (poços rasos) é feita, principalmente, por bomba elétrica (62\%); das nascentes, por gravidade, usando rego escavado ou tubo (18\%) sem proteção desde o seu afloramento até a sua captação, inclusive, sendo observada, na maioria, a presença de dejetos de animais e lixo; e a da água superficial, por bomba carneiro ou vasilhames (20\%).

Entre as análises realizadas, observou-se que todas as amostras apresentaram número de coliformes fecais acima do padrão de potabilidade pelas normas vigentes (Portaria n. 36, de 19 de janeiro de 1990 - Ministério da Saúde 18), como também das águas da classe 2 (Resolução CONAMA 19). Também ficaram fora do padrão: sólidos totais (8\%); ferro total (37\%); turbidez (68\%); cor (49\%); manganês (2\%); demanda bioquímica de oxigênio (86\%). Em relação à quantidade de coliformes fecais da água, após passar nos filtros, constatou-se que: em $52 \%$, foi menor que os da fonte; em $24 \%$, não houve diferença; em $12 \%$, foi superior; e em $12 \%$, o número de coliformes foi igual a zero.

Buscando a correlação de Pearson entre coliformes fecais, turbidez, cor e demanda bioquímica de oxigênio, só apresentaram correlação positiva a turbidez $(\mathrm{r}=0,66, \mathrm{p}<0,000)$ e demanda bioquímica de oxigênio $(r=0,56, p<0,000)$ com a cor. Desses parâmetros, apenas turbidez e cor mostraram associação com o tipo de manancial na ANOVA $(\mathrm{p}<0,05)$. Os coliformes não demonstraram correlação ou associação com nenhum desses.

\section{Comparação entre os perfis das sub-bacias dos ribeirões Água Limpa e Santa Cruz}

Neste estudo, caracterizam-se uma realidade local e condições de vida da população do meio rural do Município de Lavras, comum também a outros municípios brasileiros e levanta-se a percepção dessas comunidades sobre a qualidade da água utilizada. É uma abordagem necessária para a educação sanitária, que é uma das medidas de grande importância para o controle das doenças de veiculação hídrica $20,21,22$.

As regiões se distinguem em: tipo de propriedade ( $\mathrm{p}=0,000)$, sendo grandes fazendas, na região do Santa Cruz, em que os proprietários residem na cidade, e residências simples na região do Água Limpa; alto nível de escolaridade na região do Santa Cruz (superior) e baixo na do Água Limpa (primeiro grau) $(p=0,012)$; tipo de fonte e captação, nas quais destacamse manancial subterrâneo e captação por poços rasos através de bomba elétrica na do Água Limpa e águas superficiais e nascentes com captação por gravidade na do Santa Cruz; a atividade pecuária predominante é a bovinocultura leiteira com mão-de-obra assalariada na região do Santa Cruz e suinocultura e mão-deobra familiar na do Água Limpa $(p=0,000)$. Na 
Água Limpa, quase não há assistência técnica, e a Santa Cruz possui assistência principalmente para a atividade agrícola $(\mathrm{p}=0,011)$.

\section{Análise de água}

Pelos resultados (Tabela 2), pode-se concluir que os parâmetros coliformes fecais, turbidez e cor ficaram fora do padrão de potabilidade na maior parte das análises, segundo a legislação vigente (Portaria n. 36 18).

Em relação à qualidade do corpo d'água, pode-se verificar, de acordo com os resultados (Tabela 2), que, para os parâmetros cloretos, DBO, sólidos totais, ferro, manganês e turbidez, os mananciais enquadram-se em corpos d'água da classe 1 e, para os parâmetros oxigênio dissolvido, pH e cor, enquadram-se na classe 2. Já os resultados de coliformes fecais apresentaram valores superiores ao estipulados para as classes 1 e 2, de acordo com a Resolução CONAMA n. 357 19, desqualificando a utilização dessas águas para uso doméstico e agropecuário sem tratamento prévio.

As águas classificadas na classe 1 podem ser utilizadas para abastecimento doméstico, após tratamento simplificado, para irrigação e dessedentação de animais, sem nenhuma restrição. As águas da classe 2 podem ser utilizadas para: (1) abastecimento doméstico após tratamento convencional; (2) irrigação, sem nenhuma restrição, exceto quando a cultura for de hortaliças, devendo, assim, passar por tratamento e (3) dessedentação de animais, sem nenhuma restrição 13 .

Pelas diferenças encontradas nas análises de água, verifica-se que os parâmetros de qualidade sanitária estão mais relacionados às sub-bacias (Tabela 3). Os maiores riscos estão relacionados às atividades antrópicas, pois a sub-bacia Água Limpa, que tem densidade demográfica maior, maior uso de poços rasos (Tabela 1) e fossas, apresenta uma pior qualidade sanitária.

As diferenças entre mananciais (Tabela 3) assentam-se principalmente em aspectos físicos e químicos e se explicam pela infiltração das águas no solo e pela localização dessas águas e sua exposição à superfície, sem nenhuma proteção, e à matéria orgânica em geral.

A contaminação fecal encontrada nos mananciais estudados, inclusive os subterrâneos e sub-superficiais, deixa clara a importância desse tipo de estudo nos riscos à saúde das populações rurais e o impacto ambiental advindo das atividades humanas. Em vários levantamentos de qualidade da água consumida por diversas populações, foram encontrados riscos elevados por contaminação fecal e/ou agentes tóxicos em áreas rurais ou poços rasos urbanos 8,23,24,25,26,27,28.

Queiroz et al. 29 demonstram que populações que dependem de fontes alternativas, como poços ou que vivem em áreas rurais, estão expostas a maiores contaminações. Além de não se observar esforços das autoridades em criar, nas zonas rurais, as condições sanitárias, como nas áreas urbanas 8 , há ainda o desconhecimento dessas populações sobre a falta de qualidade sanitária da água que consomem sem tratamento 8,24,27 e o mito de que águas subterrâneas e sub-superficiais sejam potáveis.

Ao buscar as diferenças cruzadas entre mananciais e sub-bacias (Tabelas 2 e 3), observase que as sub-bacias também influenciam um maior número de parâmetros que o tipo de manancial. Porém, alguns parâmetros de importância sanitária modificam-se como, por exemplo, a demanda bioquímica de oxigênio entre os mananciais de Água Limpa e os cloretos de Santa Cruz (Tabela 2). Os parâmetros de cor e turbidez continuaram diferentes entre os mananciais em cada sub-bacia, e os coliformes mostram-se diferentes em Santa Cruz e não em Água Limpa. Isso demonstra que, em região como a do Santa Cruz, em que a atividade antrópica é menos intensa, há uma diferença esperada entre os mananciais, pois as águas superficiais sofrem maior risco de contaminação. Porém, o crescimento desordenado de habitações sem saneamento ou a falta de noções de higiene sanitária promovem a contaminação das águas subterrâneas e sub-superficiais.

Ao proceder à análise multivariada, buscando o modelo de regressão linear para turbidez e coliformes fecais, levando-se em consideração os tipos de mananciais e as sub-bacias, encontrou-se apenas o manancial superficial como fator de risco para turbidez e apenas a sub-bacia Água Limpa como fator de risco para o número de coliformes fecais (Tabela 4). Ou seja, as águas superficiais aumentam em quase três unidades a turbidez, comparadas com as águas subterrâneas, o que deve ser explicado pela infiltração. Já a qualidade sanitária não foi afetada pelos mananciais, mas apenas pela sub-bacia Água Limpa, que apresentou um aumento de 2.282n.m.p/100ml (72; 4.493) de coliformes fecais a mais que a subbacia Santa Cruz (Tabela 4), que se modifica principalmente pela ocupação do solo.

Procedendo-se a uma análise múltipla dos possíveis fatores que geram os riscos de contaminação e poluição, como as formas com que os proprietários lidam com o lixo e os dejetos, os conhecimentos e percepções de qualidade, 
Comparação entre as médias e desvio padrão dos parâmetros bacteriológicos e físico-químicos da análise de água entre os mananciais e sub-bacias estudados. Lavras, Minas Gerais, Brasil, 1999.

\begin{tabular}{|c|c|c|c|c|c|c|}
\hline Parâmetros & Mananciais & Água Limpa & $\begin{array}{l}\text { Valor } p \\
\text { manancial }\end{array}$ & Santa Cruz & $\begin{array}{l}\text { Valor } p \\
\text { manancial }\end{array}$ & $\begin{array}{c}\text { Valor } p \\
\text { sub-bacia }\end{array}$ \\
\hline Coliformes fecais & Poço raso & $4.552 \pm 5.749$ & & $23,33 \pm 20,82$ & & 0,006 \\
\hline \multirow[t]{2}{*}{ (NMP/100ml) } & Mina & $3.956 \pm 5.763$ & & $2.243 \pm 3.597$ & & 0,501 \\
\hline & Superficial & $5.140 \pm 4.889$ & 0,411 & $2.754 \pm 3.805$ & 0,032 & 0,056 \\
\hline \multirow[t]{3}{*}{ Cloretos (mg/l) } & Poço raso & $9,73 \pm 4,49$ & & $10,00 \pm 2,65$ & & 0,801 \\
\hline & Mina & $8,22 \pm 1,72$ & & $6,67 \pm 1,23$ & & 0,065 \\
\hline & Superficial & $8,69 \pm 3,2$ & 0,601 & $7,28 \pm 1,27$ & 0,031 & 0,180 \\
\hline \multirow[t]{3}{*}{$\mathrm{DBO}(\mathrm{mg} / \mathrm{l})$} & Poço raso & $0,73 \pm 0,91$ & & $0,13 \pm 0,12$ & & 0,261 \\
\hline & Mina & $1,27 \pm 0,74$ & & $0,43 \pm 0,37$ & & 0,009 \\
\hline & Superficial & $1,17 \pm 0,73$ & 0,037 & $0,57 \pm 0,38$ & 0,179 & 0,019 \\
\hline \multirow[t]{3}{*}{ Sólidos totais (mg/l) } & Poço raso & $356 \pm 878$ & & $23,33 \pm 22,55$ & & 0,073 \\
\hline & Mina & $483 \pm 1.099$ & & $35,00 \pm 83,02$ & & 0,014 \\
\hline & Superficial & $330 \pm 628$ & 0,857 & $45,00 \pm 81,82$ & 0,685 & 0,004 \\
\hline \multirow[t]{3}{*}{ Dureza total (mg/l) } & Poço raso & $46,69 \pm 42,93$ & & $40,00 \pm 26,15$ & & 0,914 \\
\hline & Mina & $41,56 \pm 23,91$ & & $17,33 \pm 29,26$ & & 0,021 \\
\hline & Superficial & $54,13 \pm 27,57$ & 0,284 & $23,67 \pm 30,25$ & 0,219 & 0,005 \\
\hline \multirow[t]{3}{*}{ Ferro total $(\mathrm{mg} / \mathrm{l})$} & Poço raso & $0,31^{\star} \pm 0,54$ & & - & & 0,038 \\
\hline & Mina & $0,10 \pm 0,10$ & & $0,91 \pm 1,27$ & & 0,255 \\
\hline & Superficial & $1,24 \pm 1,14$ & 0,008 & $0,96 \pm 0,87$ & 0,027 & 0,856 \\
\hline \multirow[t]{3}{*}{ Manganês (mg/l) } & Poço raso & $0,001 \pm 0,001$ & & - & & 0,734 \\
\hline & Mina & $0,06 \pm 0,17$ & & - & & 0,317 \\
\hline & Superficial & $0,01 \pm 0,03$ & 0,693 & $0,01 \pm 0,01$ & 0,228 & 0,271 \\
\hline \multirow[t]{3}{*}{$\mathrm{pH}$} & Poço raso & $5,28 \pm 1,0$ & & $4,99 \pm 0,34$ & & 0,474 \\
\hline & Mina & $4,88 \pm 0,61$ & & $5,81 \pm 0,58$ & & 0,009 \\
\hline & Superficial & $5,91 \pm 0,72$ & 0,001 & $6,22 \pm 0,58$ & 0,012 & 0,232 \\
\hline Oxigênio & Poço raso & $5,20 \pm 1,56$ & & $5,87 \pm 0,91$ & & 0,473 \\
\hline \multirow[t]{2}{*}{ dissolvido (mg/l) } & Mina & $5,67 \pm 2,58$ & & $6,33 \pm 1,29$ & & 0,31 \\
\hline & Superficial & $6,43 \pm 2,42$ & 0,097 & $7,64 \pm 0,87$ & 0,005 & 0,225 \\
\hline \multirow[t]{3}{*}{ Turbidez (UNT) } & Poço raso & $2,72^{\star} \pm 2,52$ & & $0,80 \pm 0,27$ & & 0,234 \\
\hline & Mina & $3,42 \pm 3,66$ & & $2,22 \pm 1,66$ & & 1,000 \\
\hline & Superficial & $6,38^{*} \pm 4,92$ & 0,043 & $4,89 \pm 2,58$ & 0,002 & 0,423 \\
\hline \multirow[t]{3}{*}{ Temperatura $\left({ }^{\circ} \mathrm{C}\right)$} & Poço raso & $23,42 \pm 2,53$ & & $26,00 \pm 1,73$ & & 0,095 \\
\hline & Mina & $23,00 \pm 3,57$ & & $20,00 \pm 3,77$ & & 0,068 \\
\hline & Superficial & $20,87 \pm 4,05$ & 0,84 & $20,17 \pm 4,18$ & 0,121 & 0,799 \\
\hline \multirow[t]{3}{*}{ Cor (mg Pt/l) } & Poço raso & $21,40^{*} \pm 59,39$ & & $5,00 \pm 0,00$ & & 0,351 \\
\hline & Mina & $31,11 \pm 36,04$ & & $15,56 \pm 31,67$ & & 0,092 \\
\hline & Superficial & $75,67 \pm 61,20$ & 0,000 & $37,78 \pm 20,38$ & 0,002 & 0,047 \\
\hline
\end{tabular}

Valor p - Kruskal-Wallis.

* Retirado um valor extremo. 
Parâmetros associados à sub-bacia ou ao tipo de manancial na zona rural de Lavras, Minas Gerais, Brasil, 1999-2000.

\begin{tabular}{|c|c|c|c|c|}
\hline Univariada & $\begin{array}{l}\text { Parâmetros } \\
\text { químicos }\end{array}$ & Valor de $p$ & $\begin{array}{l}\text { Parâmetros físicos } \\
\text { e bacteriológicos }\end{array}$ & Valor de $p$ \\
\hline \multirow[t]{5}{*}{ Sub-bacia } & Cloretos (mg/l) & 0,034 & $\begin{array}{l}\text { Coliformes fecais } \\
\text { NMP/100ml }\end{array}$ & 0,030 \\
\hline & $\mathrm{DBO}(\mathrm{mg} / \mathrm{l})$ & 0,023 & Temperatura ${ }^{\circ} \mathrm{C}$ & 0,017 \\
\hline & Oxigênio dissolvido (mg/l) & 0,000 & Sólidos totais mg/l & 0,000 \\
\hline & Dureza total (mg/l) & 0,000 & - & - \\
\hline & $\mathrm{pH}$ & 0,002 & - & - \\
\hline \multirow[t]{3}{*}{ Manancial } & Ferro (mg/l) & 0,000 & Turbidez UNT & 0,001 \\
\hline & $\mathrm{pH}$ & 0,000 & Cor mg Pt/l & 0,000 \\
\hline & Oxigênio dissolvido (mg/l) & 0,000 & Temperatura ${ }^{\circ} \mathrm{C}$ & 0,001 \\
\hline
\end{tabular}

Tabela 4

Variáveis dependentes e preditores que permaneceram nos modelos de regressão múltiplos.

\begin{tabular}{llcc}
\hline Variáveis dependentes & Fatores de risco & $\beta$ & Valor de p \\
\hline Turbidez (Modelo 1) & Manancial superficial & $2,907(1,471-4,342)^{\star}$ & $<0,000$ \\
Coliformes fecais (Modelo 2) & Sub-bacia Água Limpa & $2282(72-4493)^{\star}$ & 0,043 \\
Coliformes fecais (Modelo 3) & Utiliza tratamento & $5,934( \pm 2,4)^{\star \star}$ & 0,017
\end{tabular}

Variáveis excluídas dos modelos: 1. Sub-bacia Água Limpa; 2. Manancial superficial e;

3. Escolaridade, tipo de propriedade, possui criação animal, possui cultura agrícola, desinfeta a fonte,

número de banheiros, possui assistência técnica, possui fossa, tipo de manancial, sub-bacia.

* Regressão linear.

** Regressão logística.

presença de animais e tratamentos utilizados, definiu-se um modelo para coliformes fecais como variável dependente, em que restou apenas a presença de tratamento como significativo, com alta OR =5,93 ( $p=0,017)$, como era de esperar-se (Tabela 4).

Vários autores relatam que as condições sanitárias podem afetar a saúde da população 1,2, $3,4,5,8$ e trazer, como reflexos, maiores gastos hospitalares, que, no Brasil, demonstraram queda no período de 1996-1998, mas recrudesceram em 1999, com diferentes perfis regionais. As diarréias representaram $90 \%$ das causas dessas internações 30 .

No Município de Lavras, o índice de habitantes servidos com água encanada é de 99,2\% e de esgoto, de $85 \%$ na zona urbana 31 . Na zona rural, onde a população segundo o Instituto Brasileiro de Geografia e Estatística (IBGE) 10 é de 4.660 habitantes, não se encontraram dados sobre o abastecimento ou a qualidade de água e nem sobre as formas de destino de dejetos ou águas residuárias. Nesse estudo, demonstrou-se a baixa qualidade da água utilizada para consumo doméstico e agropecuário nessa região.

Há pouca informação sobre saneamento e incidência de doenças de veiculação hídrica nas comunidades rurais no Brasil. Segundo Szwarcwald et al. ${ }^{32}$, que estudaram a estimação da mortalidade infantil, quanto menor o nível de agregação geográfica, maior é o erro nas estimativas por mensuração indiretas fornecidas pelos municípios. Esse é mais um dos aspectos que dificultam o conhecimento da realidade sanitária existente nas áreas rurais e que afetam a saúde dessas populações. Devese perceber que a qualidade sanitária rural também afeta a saúde de populações urbanas e as condições quali-quantitativas dos manan- 
ciais a serem tratados para fornecimento da água urbana, como é o caso de Lavras, já que as áreas rurais produzem os hortifrutigranjeiros, muitas vezes, consumidos in natura.

A Constituição da República, as Constituições Estaduais e Leis Orgânicas Municipais abordam a matéria, considerando o saneamento e a salubridade ambiental direitos do cidadão a serem assegurados pelo Estado. Porém, nas primeiras décadas do século XX, os sanitaristas caracterizaram nossos sertanejos como um povo doente e analfabeto, abandonado pelo Estado e entregue à própria sorte, demonstrando a necessidade urgente de integrar essas populações aos marcos da nacionalidade e cidadania, conferindo-lhes condições de lutar pela sua própria vida 7 . No século XXI, ainda se pode observar a grande desigualdade do acesso à saúde e educação em populações rurais.

\section{Considerações finais}

Há grande desconhecimento e despreparo para as práticas higiênico-sanitárias, observadas nas formas de destinação de lixo, água servida, dejetos e embalagens utilizadas e, ainda, na falta de preocupação com a qualidade da água consumida, que se baseia principalmente em características físicas e organolépticas.

Neste estudo, demonstrou-se que a educação sanitária independe da escolaridade. Isso determina que a educação em saúde deve ser mais bem desenvolvida nas escolas, para que as pessoas aprendam medidas sanitárias e preventivas. E, ainda, que programas atuais de Educação em Saúde não deixem de lado aqueles com alto grau de escolaridade, pois esses também podem ser desinformados para as questões de saúde.

Um aspecto que deve ser bastante desenvolvido na percepção de populações rurais, ou que utilizem fontes de água que não sejam submetidas ao tratamento clássico, é que as águas subterrâneas e sub-superficiais merecem a mesma preocupação de tratamento que as águas superficiais em locais onde há alta ocupação humana.

Por tudo isso, há necessidade de estabelecer-se prioridades sanitárias também às populações rurais, que, além de suas necessidades, também interferem na qualidade e quantidade dos mananciais que abastecem a área urbana, pela forma como utilizam os produtos agrícolas e cuidam das matas ciliares e nascentes.

\section{Conclusões}

As duas regiões estudadas distinguem-se quanto ao nível de escolaridade, tipo de propriedade, manancial e captação, atividade pecuária predominante e mão-de-obra. Essas demonstram que a ocupação do solo e atividades antrópicas foram mais importantes para a determinação da qualidade sanitária da água que o tipo de manancial na região estudada.

De forma geral, a água utilizada para consumo doméstico, dessedentação de animais e irrigação de culturas oferece risco à saúde da população estudada, sendo que não houve relação entre os tipos de mananciais com o nível de contaminação por coliformes fecais. Os níveis de contaminação mais encontrados foram os da classe 2, 3 e 4 . Foi encontrada relação apenas da qualidade física da água (cor e turbidez) com os tipos de mananciais, sendo que as águas superficiais apresentam pior qualidade física que as águas subterrâneas e sub-superficiais. Portanto, o uso de água de poços rasos para consumo doméstico, dessedentação de animais e irrigação de culturas não é recomendado sem adequado tratamento.

O desconhecimento higiênico-sanitário da população estudada é nítido nas formas de destinação do lixo, de dejetos e águas residuárias e na falta de percepção da importância dos aspectos microbiológicos da qualidade das águas de consumo doméstico e agropecuário. Não foi evidenciada relação entre o grau de escolaridade e o conhecimento dos proprietários sobre tratamento doméstico de água. 


\section{Resumo}

Realizaram-se entrevistas e análises laboratoriais de 80 amostras de água em 45 propriedades rurais das sub-bacias dos ribeirões Água Limpa e Santa Cruz, em Lavras, Minas Gerais, Brasil, para comparar a qualidade da água para consumo doméstico e agropecuário e seus fatores determinantes. Na sub-bacia Água Limpa, as propriedades são principalmente caracterizadas como moradia, e seus proprietários apresentam baixo grau de escolaridade. Quanto à sub-bacia Santa Cruz, nas propriedades, explora-se a agropecuária, e a maior parte dos proprietários reside na cidade. Com relação aos graus de escolaridade, ela se apresenta muito baixa ou com nível superior. O abastecimento d'água na sub-bacia Água Limpa provém principalmente de lençóis freáticos, enquanto, na sub-bacia Santa Cruz, predominam as águas superficiais, estando seus mananciais contaminados. A percepção dos proprietários sobre a potabilidade da água relacionase às características físicas e organolépticas, não à sanitária. Não há relação entre a contaminação fecal e o tipo de manancial, mas sim com a ocupação do solo e as atividades antrópicas.

Saneamento Rural; Qualidade da Água; Consumo Doméstico de Água

\section{Colaboradores}

C. M. B. M. Rocha e L. S. Rodrigues participaram de todas as etapas da elaboração do artigo. C. C. Costa contribuiu na organização e discussão dos resultados das análises laboratoriais de água. P. R. Oliveira e I. J. Silva colaboraram na elaboração do artigo, principalmente na discussão e forma de apresentação. E. F. M. Jesus e R. G. Rolim participaram na montagem de bancos de dados, análises e relatório final do projeto para Fundação e Amparo à Pesquisa do Estado de Minas Gerais, do qual foram utilizados os resultados e algumas discussões. Além disso, participaram na correção do artigo enviado para esta revista.

\section{Agradecimentos}

Financiamento e bolsas (BIC e Aperfeiçoamento) pela Fundação e Amparo à Pesquisa do Estado de Minas Gerais.

\section{Referências}

1. Waldman EA, Barata RC, Moraes JC, Guibu IA, Timenetsky MC. Gastroenterites e infecções respiratórias agudas em crianças menores de 5 anos, em área da região Sudeste do Brasil, 1986-1987. II - diarréias. Rev Saúde Pública 1997; 31:62-70.

2. Barcellos C, Coutinho K, Pina MF, Magalhães MM, Paola JC, Santos SM. Inter-relacionamento de dados ambientais e de saúde: análise de risco à saúde aplicada ao abastecimento de água no Rio de Janeiro utilizando Sistemas de Informações Geográficas. Cad Saúde Pública 1998; 14: 597-605.

3. Moza PG, Pieri OS, Barbosa CS, Rey L. Fatores sócio-demográficos e comportamentais relacionados à esquistossomose em uma agrovila da zona canavieira de Pernambuco. Cad Saúde Pública 1998; 14:107-15.

4. Soares SR, Bernardes RS, Netto OM. Relações entre saneamento, saúde pública e meio ambiente: elementos para formulação de um modelo de planejamento em saneamento. Cad Saúde Pública 2002; 18:1713-24.

5. Heller L, Colosimo AE, Antunes CMF. Environmental sanitation conditions and health: impact:a case-control study. Rev Soc Bras Med Trop 2003; 36:41-50.

6. Silva AM. Tratamento de água. Lavras: Editora UFLA; 1977.

7. Hochman G. A era do saneamento. São Paulo: Editora Hucitec/Associação Nacional de Pósgraduação e Pesquisa em Ciências Sociais; 1998.

8. Amaral LA, Nader Filho A, Rossi Junior OD, Ferreira LAF, Barros LSS. Água de consumo humano com fator de risco à saúde em propriedades rurais. Rev Saúde Pública 2003; 37:510-4.

9. Hidrosistemas. Elaboração do plano de proteção e preservação dos mananciais utilizados para abastecimento de água de Lavras. Lavras: Hidrosistemas; 1997.

10. Instituto Brasileiro de Geografia Estatística. Censo agropecuário de Minas Gerais. Rio de Janeiro: Instituto Brasileiro de Geografia e Estatística; 1996. (Censos Econômicos 8, parte 1).

11. Ministério da Agricultura e Reforma Agrária. Normas climatológicas 1961-1990. Brasília: Ministério da Agricultura e Reforma Agrária; 1992.

12. Clescerl LS, Greenberg AE, Eaton AD. Standard methods for the examination of water and wastewater. 18th Ed. Washington DC: American Public Health Association; 1992.

13. von Sperling M. Introdução à qualidade das águas e ao tratamento de esgotos. 3a Ed. Belo Horizonte: Departamento de Engenharia Ambiental, Universidade Federal de Minas Gerais; 2005.

14. Rocha CMBM. Caracterização da percepção dos produtores de leite do Município de Divinópolis/ MG sobre a importância do carrapato Boophilus microplus e fatores determinantes das formas de combate utilizadas [Dissertação de Mestrado]. Belo Horizonte: Escola de Veterinária, Universidade Federal de Minas Gerais; 1995.

15. Triviños ANS. Introdução à pesquisa em ciências sociais: a pesquisa qualitativa em educação. São Paulo: Editora Atlas; 1987. 
16. Gil AC. Métodos e técnicas de pesquisa social. São Paulo: Editora Atlas; 1991.

17. Minayo MCS. O desafio do conhecimento: pesquisa qualitativa em saúde. 2ạ Ed. São Paulo: Editora Hucitec/Rio de Janeiro: ABRASCO; 1993.

18. Brasil. Portaria n. 36 do Ministério da Saúde, de 19 de janeiro de 1990. Diário Oficial da União 1990; 23 jan.

19. Brasil. Resolução CONAMA n. 357/2005. Dispõe sobre a classificação dos corpos de água e diretrizes ambientais para o seu enquadramento, bem como estabelece as condições e padrões de lançamento de efluentes, e dá outras providências. Diário Oficial da União 2005; 18 mar.

20. Mello DA, Rouquayrol MZ, Araújo D, Amadei M, Souza J, Bento, LF, et al. Promoção à saúde e educação: diagnóstico de saneamento através da pesquisa participante articulada à educação popular (Distrito São João dos Queiroz, Quixadá, Ceará, Brasil). Cad Saúde Pública 1998; 14:583-95.

21. Gazzinelli MF, Gazzinelli A, Santos RV, Gonçalves LAO. A interdição da doença: uma construção cultural da esquistossomose em área endêmica, Minas Gerais, Brasil. Cad Saúde Pública 2002; 18: 1629-38.

22. Gomes R, Mendonça EA, Pontes ML. As representações sociais e a experiência da doença. Cad Saúde Pública 2002; 18:1207-14.

23. Bevilacqua PD, Bastos RKX, Heller L, Oliveira AA, Vieira MBCM, Brito LL. Perfil parasitológico e qualidade da água para consumo humano: aplicação da metodologia da avaliação de risco. Rev Bras Epidemiol 2002; Suplemento Especial:454.

24. Silva RCA, Araújo TM. Consumo humano da água do manancial subterrâneo em duas áreas urbanas de Feira de Santana-BA/2000. Perfil dos consumidores. Rev Bras Epidemiol 2002; Suplemento Especial:457.

25. Silva RLB, Barra CM, Monteiro TCN, Brilhante OM. Estudo da contaminação de poços rasos por combustíveis orgânicos e possíveis conseqüências para a saúde pública no Município de Itaguaí, Rio de Janeiro, Brasil. Cad Saúde Pública 2002; 18:1599-607.
26. Amaral LA, Rossi Jr. OD, Nader Filho A, Alexandre AV. Avaliação da qualidade higiênico-sanitária de poços rasos localizados em uma área urbana: utilização de colifagos em comparação com indicadores bacterianos da poluição fecal. Rev Saúde Pública 1994; 28:345-8.

27. Giatti LL, Rocha AA, Santos FA, Bittencourt SC, Pieroni SR. Condições de saneamento básico em Iporanga, Estado de São Paulo. Rev Saúde Pública 2004; 38:571-7.

28. Instituto Brasileiro de Geografia Estatística. Pesquisa Nacional de Saneamento Básico. Rio de Janeiro: Instituto Brasileiro de Geografia e Estatística; 2000.

29. Queiroz MF, Cardoso MCS, Santana EM, Gomes $\mathrm{AB}$, Rique SMN, Lopes CM. A qualidade da água de consumo humano e as doenças diarréicas agudas no Município do Cabo de Santo Agostinho, PE. Rev Bras Epidemiol 2002; Suplemento Especial:456.

30. Pontes CAA, Costa AM, Castro CCL, Melo CH, Lucena RCB, Gonçalves FR, et al. Impactos decorrentes de agravos relacionados a um saneamento ambiental inadequado sobre gastos hospitalares do Sistema Único de Saúde, Brasil, 1996 a 2000. Rev Bras Epidemiol 2002; Suplemento Especial: 456.

31. Prefeitura Municipal de Lavras. Plano municipal de assistência social de Lavras. Lavras: Prefeitura Municipal de Lavras; 1997.

32. Szwarcwald CL, Leal MC, Andrade CLT, Souza Jr. PRB. Estimação da mortalidade infantil no Brasil: o que dizem as informações sobre óbitos e nascimentos do Ministério da Saúde? Cad Saúde Pública 2002; 18:1725-36.

Recebido em 04/Jan/2005

Versão final reapresentada em 29/Nov/2005

Aprovado em 06/Dez/2005 